\title{
SYNCHRONOUS BILATERAL INTRACYSTIC PAPILLARY AND INVASIVE DUCTAL BREAST CARCINOMA IN A YOUNG FEMALE: A RARE ENTITY
}

\author{
Imtiaz S, Irshad M, Usman R, Saad M \\ Department of Radiology, Dr. Ziauddin University Hospital, Karachi, Pakistan \\ DOI: http://doi.org/10.4038/sljr.v3i1.35
}

Keywords:Breast, papillary Carcinoma, invasive ductal, young female

\section{Introduction}

Intracystic papillary breast carcinoma is a rare entity of invasive breast cancer accounting for approximately $0.5 \% .^{1}$ It is most frequently seen in elderly postmenopausal women with age range between 55- 76 years. It also occurs in males and is the second most common cause of breast carcinoma in males. ${ }^{2}$ Only a few cases of intracystic papillary carcinoma of breast has been reported in women less than 40 years of age. ${ }^{3}$ This article reports a case of synchronous bilateral intracystic papillary carcinoma and invasive ductal carcinoma of breast in a 34 year old female. Its occurrence in a young female is noteworthy.

\section{Case report}

A 34-year-old female presented to the radiology department for bilateral mammogram examination during her postpartum period with a history of a painless lumps in right peri-areolar region and in upper inner quadrant of left breast for 2-3 years. Initially, the lesions had been small, but had greatly increased in size during pregnancy especially the left breast lesion. She also complained of mild bilateral nipple discharge. On examination, firm to hard lesions were palpable which were partially fixed to the underlying structures. Overlying skin was normal without evidence of nipple retraction. She had a positive family history of breast carcinoma.

Standard cranio-caudal (CC) and mediolateral oblique (MLO) views of both breasts were done. Markers were placed at the site of palpable lumps. Mammogram demonstrated bilateral dense breast parenchyma. In right breast, a well defined, small, isodense oval shaped mass was seen in periareolar location with a smooth margin. In left breast, a large well circumscribed isodense mass was present in upper inner quadrant, with slightly indistinct margins along its superior aspect merging with the breast parenchyma. There was no evidence of surrounding architectural distortion, skin thickening or nipple retraction. No pleomorphic micro calcifications were present (Fig. 1).

Corresponding Author: Imtiaz S <dr.sheeza.imtiaz@gmail.com>

https://orcid.org/0000-0003-3044-0237

This is an open-access article distributed under the terms of the Creative Commons Attribution 4.0 International License, which permits unrestricted use, distribution and reproduction in any medium provided the original author and source are credited. 


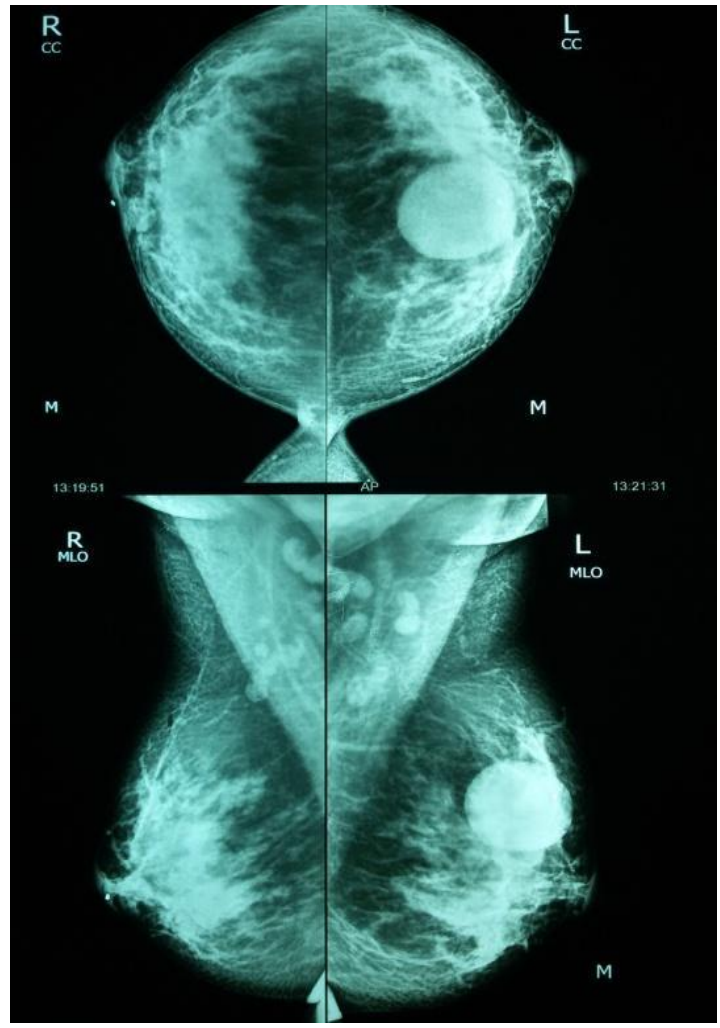

Figure 1: Bilateral mammogram (CC and MLO views). Well defined soft tissue lesion in periareolar region of right breast and a large well defined soft tissue lesion in upper inner quadrant of left breast with slightly indistinct superior margins merging with breast parenchyma.

On ultrasound examination, a well defined oval shaped hypoechoic cystic lesion was seen in periareolar region of right breast measuring $1.1 \times 0.6 \mathrm{~cm}$ with intracystic solid component. (Fig. 2). A few small hypoechoic masses were also present at 10-12 o'clock position. In the left breast, a large well defined oval shaped, thick walled, cystic lesion was seen at 10-12 o'clock position measuring $2.8 \times 2.4 \mathrm{~cm}$. Diffuse low level internal echoes and a solid component were noted within it. Another tubular area was seen communicating with it showing large solid component in it reaching up to areola (Fig.3).

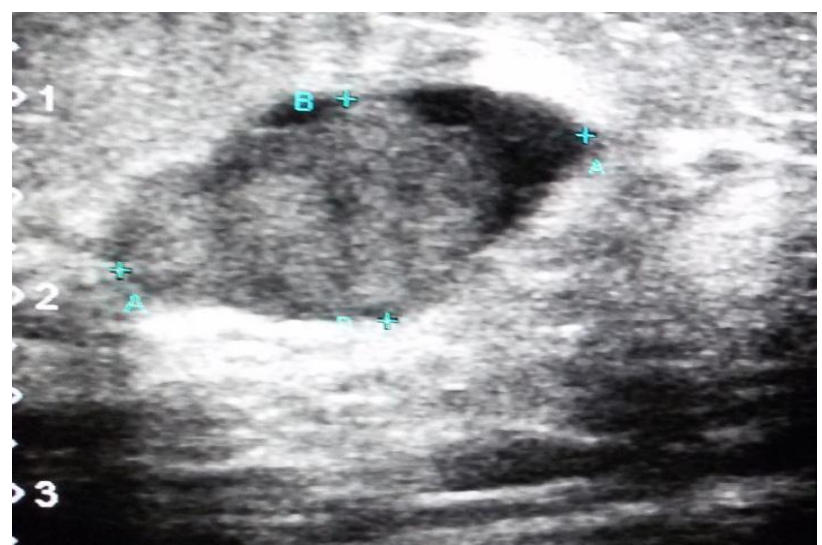

Figure 2: Ultrasound examination of right breast - an oval shaped lesion with central solid component.

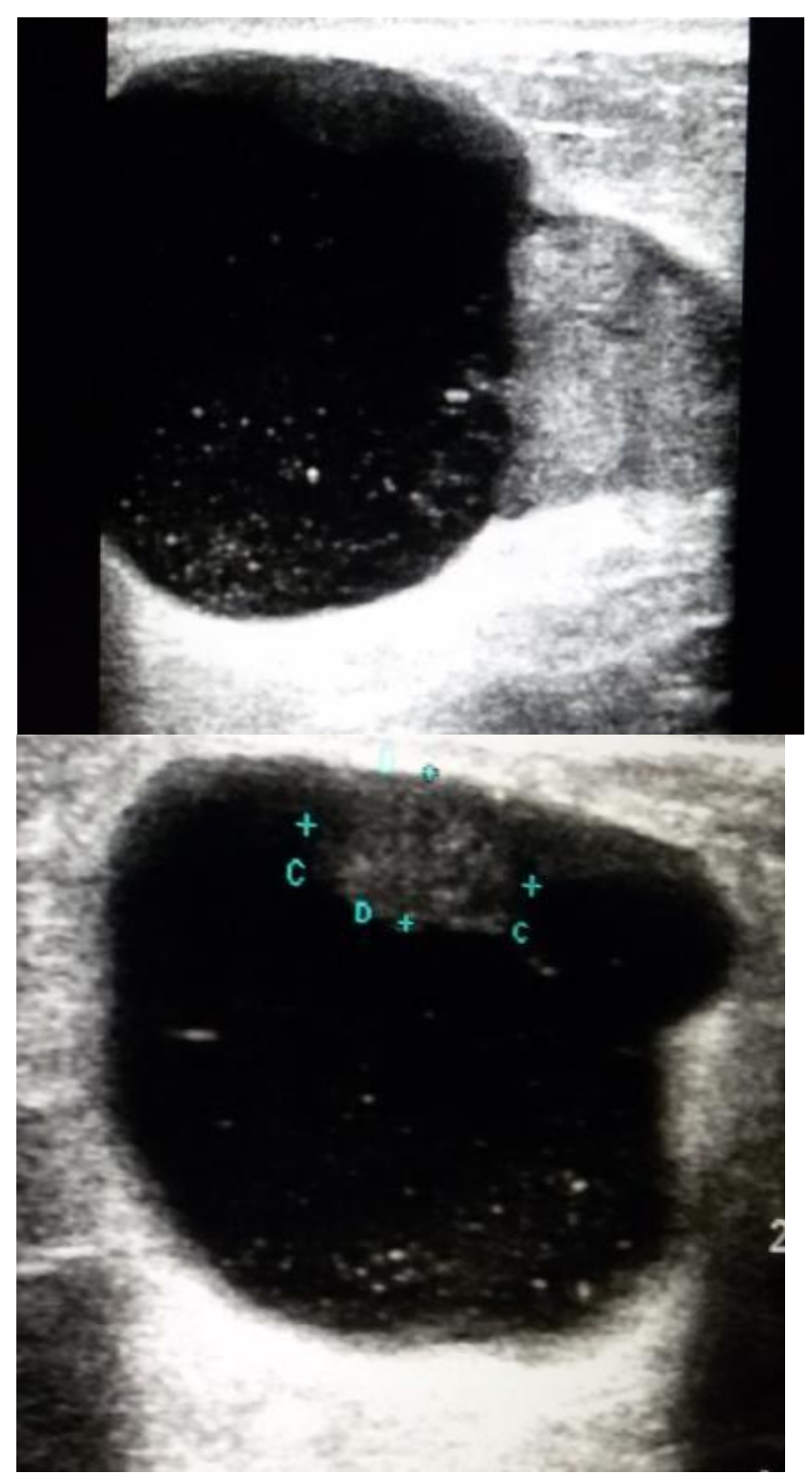

Figure. 3: Ultrasonography of left breast. A well defined thick walled cystic lesion measuring with a solid mural component. Diffuse low level echoes representing intracystic tumoral hemorrhage. 
Increased vascularity was noted within the solid component on color Doppler. Imaging appearances of both masses were suggestive of suspicious lesions (BIRADS Category 4). Biopsy of the lesions revealed bilateral intracystic papillary carcinoma along with invasive ductal carcinoma.

\section{Discussion}

Encapsulated papillary carcinoma, also known as intracystic papillary carcinoma (IPC), is the term used to describe a solitary, centrally located malignant papillary proliferation involving a cystic dilatation of a duct. Carter et al. $^{4}$ classified papillary carcinomas in to invasive and non invasive types. Non invasive type is further divided into two types. Diffuse form, as an intracystic variety of ductal carcinoma in situ (DCIS) and localized form as intracystic papillary carcinoma. IPC is further sub divided into three categories. IPC alone (pure form), IPC along with DCIS and IPC with invasive carcinoma. These lesions usually present as a painless mass for long duration with bloody nipple discharge.

On mammography, papillary carcinomas mostly present as well circumscribed round, oval or lobulated lesions. They have smooth margins but may show indistinct margins at sites of local invasion. There are no spiculations and axillary lymphadenopathy is infrequent. Mammographic differentials would include benign cyst, haematoma, invasive ductal carcinoma, colloid or medullary carcinoma.,

On ultrasonography, papillary carcinoma show three basic profiles: (a) complex anechoic cystic mass with internal echogenic solid component showing vascularity within solid component on color Doppler (b) intraductal mass with or without duct dilatation (c) solid pattern with an intraductal mass completely filling the duct. They may show microlobulation with indistinct margins. Large solid components have a higher incidence of intracystic hemorrhage giving rise to internal echoes. ${ }^{6}$ The cystic portion may show septations. Heterogeneous echotexture, and irregular border of the solid papillary mass and intracystic vegetations are criteria suspicious of malignancy.

MRI is sensitive but not specific in diagnosing papillary lesions. Contrast enhanced study may show enhancement of cyst wall, septations and solid mural components. $^{6}$

Recent literature reveals that IPC is associated with DCIS and invasive breast carcinomas in $40 \%$ of the cases. ${ }^{3}$ IPC are usually low to intermediate grade tumors on histopathology without necrosis. However, if associated with invasive cancers they are found to be of nuclear grade three with necrosis. $^{7}$ On immunohistochemistry, these are usually estrogen receptor, and progesterone receptor (ERPR) positive and show negative Her2Neu. ${ }^{8}$

Ultrasound guided core needle biopsy of intracystic lesion has usually false negative results as the site of biopsy is central and invasion is mostly seen at the periphery of the lesion. Complete local excision of the tumor with clear margins is the most appropriate surgical treatment with or without adjuvant radiotherapy. Mastectomy may also be another management option. ${ }^{9}$ Metastasis to axillary lymph nodes may occur in $14 \%$ of the cases, ${ }^{10}$ therefore, an axillary staging procedure or clearance is recommended. Axillary intervention includes dissection or sentinel lymph node biopsy. 
This case is unique due to synchronous and bilateral involvement. Furthermore, it is coexistent with invasive ductal carcinoma which has been reported in the literature to be associated with it in only $40 \%$ of the cases.

Papillary carcinomas are low grade, slow growing tumors with relatively better prognosis showing a $100 \%$ survival rate at 10 years and disease free survival of $91 \%$.

It is a rare variety of breast carcinoma and often mimics a benign lesion clinically, therefore, it should be kept in mind as a differential diagnosis in palpable breast lumps. A high clinical suspicion with triple assessment is necessary for diagnosis.

\section{Conflicts of interest}

Authors declare no conflicts of interest.

\section{Acknowledgement}

Would like to acknowledge the contribution of all the members of radiology department of Dr. Ziauddin University Hospital for their support.

\section{References}

1. Louwman MWJ, Vriezen M, Beek MWPMv, Nolthenius-Puylaert MCBJET, Sangen MJCvd, Roumen RM, et al. Uncommon breast tumors in perspective: Incidence, treatment and survival in the Netherlands. International Journal of Cancer. 2007;121(1):127-35.

2. Grabowski J, Salzstein SL, Sadler GR, Blair S. Intracystic papillary carcinoma: a review of 917 cases. Cancer.2008;113 (5):916-920.

3. Baykara M, Coskun U, Demirci U, Yildiz R, Benekli M, Cakir A, Buyukberber S. Intracystic papillary carcinoma of the breast: one of the youngest patients in the literature. Med Oncol. 2010;27(4):1427-8.

4. Carter D, Orr SL, Merino MJ. Intracystic papillary carcinoma of the breast. After mastectomy, radiotherapy or excisional biopsy alone. Cancer. 1983;52(1):14-9.

5. Brookes MJ, and AG. Bourke. Radiological appearances of papillary breast lesions. Clinical Radiology. 2008;639(11):1265-73.

6. Rosen PP. Papillary carcinoma; Rosen's Breast Pathology. Lippincott-Ravel Publishers. Philadelphia, Pa, USA. 1997: 335-54.

7. Leal C, Costa I, Fonseca D, Lopes P, Bento MJ, Lopes C. Intracystic (encysted) papillary carcinoma of the breast: a clinical, pathological, and immunohistochemical study. Hum Pathol. 1998;29(10):1097-104.

8. Yoshimura N, Murakami S, Kaneko $M$, Sakatani A, Hirabayashi N, Takiyama W. Synchronous bilateral solid papillary carcinomas of the breast. Case Rep Surg. 2013; 2013:8121-29.

9. Solorzano CC, Middleton LP, Hunt KK, Mirza N, Meric F, Kuerer HM, Ross MI, Ames FC, Feig BW, Pollock RE, Singletary SE, Babiera G. Treatment and outcome of patients with intracystic papillary carcinoma of the breast. Am J Surg. 2002;184(4):364-8.

10. Grabowski J, Salzstein SL, Sadler GR, Blair S. Intracystic papillary carcinoma: a review of 917 cases. Cancer. 2008;113(5):916-20. 